\title{
Reevaluation of reference values for bone marrow differential counts in 236 healthy bone marrow donors
}

\author{
Stefani Parmentier ${ }^{1} \cdot$ Michael Kramer ${ }^{2} \cdot$ Swetlana Weller $^{2} \cdot$ Ulrich Schuler $^{2} \cdot$ Rainer Ordemann $^{2} \cdot$ Gabi Rall $^{3}$. \\ Markus Schaich $^{1} \cdot$ Martin Bornhäuser $^{2} \cdot$ Gerhard Ehninger $^{2} \cdot$ Frank Kroschinsky $^{2}$ (D)
}

Received: 3 July 2020 / Accepted: 1 September 2020 / Published online: 15 September 2020

(C) The Author(s) 2020

\begin{abstract}
Despite the increasing role of molecular markers, differential counts and morphology of hematopoietic cells in the bone marrow (BM) remain essential diagnostic criteria in hematological diseases. However, the respective reference values for BM myelogram commonly used came from small series with limited numbers of healthy individuals. We evaluated the myelograms of 236 healthy individuals who underwent unrelated bone marrow donation. Health check-ups were performed 4 weeks prior to harvest. Samples for this study, taken from the first aspiration, were stained according to the standard Pappenheim method. Three experienced investigators assessed cellularity, megakaryopoiesis, and differential counts independently. The median donor age was 31 (range 18-51) years. Predonation tests did not reveal any relevant morbidity. Thirty-seven out of 42 hypocellular marrow samples were from younger donors up to 39 years. Content of megakaryocytes was normal in 210 specimens (89\%). Gender and body mass index had significant impact on hematopoiesis, whereas age had not. The number of erythroblasts was higher (about $32 \%$ ) and the proportion granulopoiesis slightly lower (about 50\%) compared with previous studies. Differential counts showed also some differences with respect to individual maturation stages in these lines. Interrater comparisons showed greater reliability for the assignment of cells to the different hematopoietic cell lines than for single-cell diagnoses. This study largely confirms the results for cell counts in normal human bone marrow available from previous reports and provides some insights into factors that affect individual cell populations. It also reveals substantial variability among even experienced investigators in cytological diagnoses.
\end{abstract}

Keywords Bone marrow $\cdot$ Cytology $\cdot$ Hematopoiesis $\cdot$ Normal differential counts

\section{Introduction}

In 1944, E. E. Osgood and A. J. Seaman described a differential count of bone marrow (BM) aspirates from 12 healthy men, which since then has been cited as a reference in Wintrobe's Clinical Hematology [1, 2]. Fifty-seven years later, Barbara Bain assessed the percentage of cells in freshly obtained, non-anticoagulated bone marrow smears of 50 healthy subjects [3]. The cohort included 30 men and 20

Frank Kroschinsky

frank.kroschinsky@ukdd.de

1 Department of Hematology, Oncology and Palliative Care, Rems-Murr-Hospital, Winnenden, Germany

2 Medical Department I, University Hospital Dresden, Fetscherstr. 74, 01307 Dresden, Germany

3 DKMS German Bone Marrow Donor Center, Tübingen, Germany women, aged between 21 and 56 years, who were in good health and free of current infection and allergic conditions. The most recent results of normal myelograms from 140 healthy subjects were presented by Diem et al. in 2012 [4]. Until today, most laboratories rely on these normal BM values obtained from only limited numbers of healthy subjects.

More than 100 bone marrow harvests from healthy unrelated donors are performed every year at Dresden University Hospital. We gathered marrow squash slides from over 400 individuals of this cohort harvested over a 4-year period at our institution to investigate myelopoiesis.

Despite the huge increase in knowledge on molecular pathogenesis and the use of these findings in diagnostic algorithms, bone marrow examination remains the gold standard for diagnosing and monitoring in hematological diseases, and normal bone marrow counts remain the basis for understanding and proper evaluation of pathological bone marrow changes. The aim of our study was to re-evaluate the myelogram in a 
larger population of healthy individuals to confirm or improve the available evidence, and to make hematological diagnostics more reliable.

\section{Design and methods}

\section{Donors and harvests}

Over a 4-year period, we gathered BM slides from 445 healthy subjects who underwent unrelated bone marrow donation at our institution on behalf of the German Bone Marrow Donor Center (DKMS). For this study, we randomly selected marrow samples of 236 individuals out of this cohort to evaluate retrospectively health data, blood counts, and marrow hematopoiesis.

All volunteers underwent predonation health check-ups about 4 weeks prior to the harvest including health history, physical examination, and chest $\mathrm{x}$-ray. Laboratory analyses included fully automated peripheral blood counts (Sysmex XE-2100, Sysmex Europe GmbH, Norderstedt, Germany), common chemistry tests for liver and renal function, C-

Table 1 Demographic data of study population $(N=236)$

\begin{tabular}{|c|c|c|}
\hline Feature & $\operatorname{nav}[n]$ & $n(\%)$ \\
\hline Male/female & 236 & $165(70) / 71(30)$ \\
\hline Age cohorts & 236 & \\
\hline$<30$ years & & $112(47)$ \\
\hline 30-39 years & & $71(30)$ \\
\hline$\geq 40$ years & & $53(22)$ \\
\hline Body mass index & 235 & \\
\hline$<25 \mathrm{~kg} / \mathrm{m}^{2}$ & & $121(51)$ \\
\hline $25-29 \mathrm{~kg} / \mathrm{m}^{2}$ & & $84(36)$ \\
\hline$\geq 30 \mathrm{~kg} / \mathrm{m}^{2}$ & & $30(13)$ \\
\hline Smoking status & 232 & \\
\hline Non-smoker & & $162(70)$ \\
\hline Smoker & & $70(30)$ \\
\hline Physical activity & 93 & \\
\hline Regularly & & $57 / 93(61)$ \\
\hline Not regularly & & 36/93 (39) \\
\hline Daily alcohol use & 230 & \\
\hline Men & & $34(21)$ \\
\hline Females & & $3(4)$ \\
\hline Allergic diathesis in history & 226 & \\
\hline Yes & & $60(27)$ \\
\hline No & & $166(73)$ \\
\hline Hormonal contraception & 51 & \\
\hline Yes & & $13(25)$ \\
\hline No & & $38(75)$ \\
\hline
\end{tabular}

nav number of available observations reactive protein, and infectious disease markers $(\mathrm{EBV}$, CMV, HSV1/2, HIV, Treponema pallidum, hepatitis A, B, C). Serum ferritin was used to assess the iron homeostasis based on gender and age-adapted normal ranges. Onehundred seventy-two donors ( $72 \%$ ) underwent an autologous blood donation at the day of check-up.

Donors gave written informed consent for harvest and marrow examination. Both interventions were approved by the institutional review board (EK 240102007) of the Technical University of Dresden and procedures were in accordance with the Helsinki Declaration of 1975, as revised in 2008.

The donors had not received growth factors. Bone marrow harvests were performed under general anesthesia. The first $4 \mathrm{~mL}$ of aspirated marrow was taken for this study and mixed in a $20 \mathrm{~mL}$ syringe for anticoagulation with $1 \mathrm{~mL}$ Di-NaEDTA 1.107\% (AlleMan Pharma GmbH, final concentration of EDTA being approximately $0.22 \%$ ).

\section{Selection of samples and medical record review}

The aim in the selection of samples for this study was to ensure high slide quality and to have sufficient numbers for statistical analyses.

Medical records were reviewed and laboratory results were collected from the central laboratory server. At least weekly physical activities were categorized as "regularly." Infectious disease markers and lifestyle information were compared with data of the German standard population published by the German federal health authorities [5-9].

\section{Slide preparation and bone marrow evaluation}

Squash slides were prepared from the anticoagulated bone marrow specimens by experienced laboratory technicians within $2 \mathrm{~h}$ as recommended by the WHO [10]. MayGrunwald-Giemsa method (Pappenheim) was used for staining as previously described [11-13].

Three morphologists who are experienced in this field for many years performed bone marrow evaluation independently. Examination was based on well-established references [2, 11, 14-16]. Each investigator assessed cellularity and content of megakaryopoiesis in low power magnification (100-fold) using a Nikon Eclipse E600 Microscope. Forty to 60\% of hematopoietic cells and the presence of one to three megakaryocytes per low-power field defined cellularity and megakaryopoiesis as normal, respectively. Furthermore, the investigators each performed a 200-cell differential cell count in higher magnification (1000-fold) for a total of 600 cells per sample, which exceeded the number of 500 cells recommended by the WHO [10]. Cell counts were performed in areas containing few bare nuclei; the cells were well-spread and not overlapping, found in clusters, or artifactually distorted because of the spreading artifact. 
Table 2 Peripheral blood counts: institutional normal limits and outliers among individuals of the study population

\begin{tabular}{|c|c|c|c|c|c|c|c|}
\hline \multirow[t]{2}{*}{ Parameter } & \multicolumn{3}{|c|}{ Institutional normal limits } & \multicolumn{4}{|c|}{ Out of limits in this study } \\
\hline & Units & Lower & Upper & nav & $n(\%)$ & Lowest & Highest \\
\hline \multicolumn{8}{|l|}{ Hemoglobin } \\
\hline Female & & 7.4 & 10.7 & 71 & $0(0)$ & - & - \\
\hline Male & & 8.6 & 12.1 & 165 & $0(0)$ & - & - \\
\hline \multicolumn{8}{|l|}{ Hematocrit } \\
\hline Female & & 0.37 & 0.47 & 71 & $3(4.0)$ & 0.35 & - \\
\hline Male & & 0.40 & 0.54 & 164 & $1(0.6)$ & 0.39 & - \\
\hline $\mathrm{MCH}$ & fmol & 1.70 & 2.10 & 103 & $5(4.8)$ & 1.56 & - \\
\hline $\mathrm{MCHC}$ & $\mathrm{mmo} / \mathrm{L}$ & & & & & & - \\
\hline Female & & 20.0 & 23.0 & 43 & $1(0.9)$ & 19.7 & - \\
\hline Male & & 19.0 & 22.0 & 60 & $15(25.0)$ & - & 23.3 \\
\hline MVC & $\mathrm{fL}$ & 80 & 96 & 235 & $10(4.2)$ & 79 & 100 \\
\hline White blood cells & $\mathrm{X} 10^{\wedge} 9 / \mathrm{L}$ & 3.80 & 9.80 & 236 & $4(1.7)$ & - & 11.7 \\
\hline Neutrophils & $\mathrm{X} 10^{\wedge} 9 / \mathrm{L}$ & 1.80 & 7.55 & 233 & $3(1.3)$ & 1.74 & 8.75 \\
\hline Eosinophils & $\mathrm{X} 10^{\wedge} 9 / \mathrm{L}$ & 0 & 0.49 & 225 & $7(3.1)$ & - & 0.77 \\
\hline Basophils & $\mathrm{X} 10^{\wedge} 9 / \mathrm{L}$ & 0 & 0.20 & 223 & $0(0)$ & - & - \\
\hline Monocytes & $\mathrm{X} 10^{\wedge} 9 / \mathrm{L}$ & 0.20 & 1.00 & 229 & $4(1.7)$ & 0.12 & - \\
\hline Lymphocytes & $\mathrm{X} 10^{\wedge} 9 / \mathrm{L}$ & 1.50 & 4.00 & 233 & $37(15.9)$ & 0.73 & 4.04 \\
\hline Platelets & $\mathrm{X} 10^{\wedge} 9 / \mathrm{L}$ & 150 & 400 & 236 & $0(0)$ & - & - \\
\hline
\end{tabular}

nav number of available observations

\section{Statistical analysis}

We recorded the donors' health data, lab results, and differential counts of the marrow evaluations in a Microsoft Access data bank and then finally analyzed with the statistic program $R \circledast$ version 3.5.3. [17]. If not otherwise indicated, we report medians and means with observed ranges. The effect of different factors on hematopoietic cell lines was tested by univariate analysis using the Mann-Whitney $U$ test respective Kruskal-Wallis test in case of more than two groups. Categorical variables were compared using the $\chi^{2}$ test. A $p$ value of less than 0.05 was considered significant. The twosided $95 \%$ reference range for the physiological myelogram was estimated with sample quantile method number seven as described by Hyndman and Fan [18]. The interrater reliability was estimated using Krippendorff's alpha for interval-scaled data [19]. A value of zero indicates perfect random disagreement, whereas a value of one indicates perfect agreement. Alpha can assume negative values when coders consistently agree to disagree, follow different coding instructions or having a conflicting understanding of them. In addition, we fitted unconditional linear mixed-effects models for all continuous variables with a random intercept for the rater and calculated the models' intra-class-correlation-coefficients [20] to estimate the proportions of variance that are explained by the different investigators.

\section{Results}

\section{Donor characteristics and predonation tests}

Table 1 shows the demographic features of the study population. Median age was 31 (range 18-51) years. Preexisting health disorders did not influence suitability for donation. In some patients, the test results for clinical chemistry (liver enzymes, renal function, serum electrolytes) were slightly outside the normal range. These results had no clinical significance in any case. Neither there were donors with iron deficiency or overload.

The seroprevalences for herpes simplex virus and cytomegalovirus among the donors were less than in the German national standard population. For Epstein-Barr and varicellazoster viruses, the frequency of infections was comparable with the general population. While the proportion of smokers was representative, the cohort included fewer individuals with daily use of alcoholic beverages and more subjects with regular physical activities (data not shown).

Table 2 summarizes the assessments of peripheral blood counts based on the institutional normal limits. Hemoglobin concentration, white blood cell, and platelet counts were within the defined ranges in the great majority of donors and detected deviations were minimal. In contrast, for mean corpuscular hemoglobin concentration (MCHC) and lymphocyte 
Table 3 Results for normal bone marrow myelogram in the study cohort of 236 donors based on counting by three independent investigators (200 cells each, in total 600 cells). The right part of this table shows the results from previous reports for comparison

\begin{tabular}{|c|c|c|c|c|c|c|c|}
\hline \multirow{2}{*}{$\begin{array}{l}\text { Lineage and } \\
\text { maturation }\end{array}$} & \multicolumn{4}{|l|}{ This study } & \multirow{2}{*}{$\begin{array}{l}\text { Wintrobe } \\
(2009) \\
\text { Mean }(\%)\end{array}$} & \multirow{2}{*}{$\begin{array}{l}\text { Bain } \\
(1996) \\
\text { Mean } \\
(\%)\end{array}$} & \multirow{2}{*}{$\begin{array}{l}\text { Diem } \\
(2012 \\
\text { Mean } \\
(\%)\end{array}$} \\
\hline & $\begin{array}{l}\text { Range } \\
(\%)\end{array}$ & $\begin{array}{l}\text { Reference } \\
\text { range }(\%)\end{array}$ & $\begin{array}{l}\text { Median } \\
(\%)\end{array}$ & $\begin{array}{l}\text { Mean } \\
(\%)\end{array}$ & & & \\
\hline Erythroblasts (total) & $8.5-56.5$ & $15.8-46.2$ & 32.0 & 31.7 & 25.6 & & 23.0 \\
\hline Male & $11.0-54.5$ & $16.2-46.6$ & 33.0 & 32.4 & & 28.1 & \\
\hline Female & $8.5-56.5$ & $15.6-45.0$ & 29.5 & 30.1 & & 22.5 & \\
\hline Proerythroblast & $0-5.0$ & $0-3.0$ & 0.5 & 0.6 & 0.6 & & $<1.0$ \\
\hline Basophilic & $0-21.0$ & $0.5-13.5$ & 3.5 & 4.5 & 1.4 & & 1.0 \\
\hline Polychromatophilic & $3.0-47.0$ & $7.8-34.5$ & 20.0 & 20.2 & 21.6 & & 2.0 \\
\hline Orthochromatic & $0-21.0$ & $0.5-16.5$ & 5.5 & 6.3 & 2.0 & & 19.0 \\
\hline Granulocytes (total) & $24.5-72.5$ & $34.8-66.3$ & 49.5 & 49.9 & & & \\
\hline Male & $26.0-70.5$ & $35.5-64.5$ & 49.5 & 49.7 & & & \\
\hline Female & $24.5-72.5$ & $34.1-67.4$ & 50.0 & 50.5 & & & \\
\hline Neutrophils (total) & & & & & 53.6 & & 55.0 \\
\hline Myeloblast & $0-8.5$ & $0-5.0$ & 1.5 & 1.6 & 0.9 & 1.4 & 2.0 \\
\hline Promyelocyte & $0-8.5$ & $0-5.5$ & 1.0 & 1.3 & 3.3 & 7.8 & 2.0 \\
\hline Myelocyte & $1.0-31.7$ & $5.8-24.0$ & 13.5 & 13.7 & 12.7 & 7.6 & 3.0 \\
\hline Metamyelocyte & $0.5-18.0$ & $1.0-12.0$ & 4.5 & 5.0 & 15.9 & 4.1 & 9.0 \\
\hline Band & $2.0-34.0$ & $6.5-26.2$ & 14.5 & 15.2 & 12.4 & 32.1(m), & 10.0 \\
\hline Segmented & $1.0-27.5$ & $2.5-19.7$ & 9.5 & 9.8 & 7.4 & $37.4(\mathrm{f})$ & 29.0 \\
\hline Eosinophils (total) & $0-18.0$ & $0.5-7.0$ & 2.5 & 3.0 & 3.1 & 3.5 & 4.0 \\
\hline $\begin{array}{l}\text { Basophils (and mast } \\
\text { cells) }\end{array}$ & $0-3.0$ & $0-1.5$ & 0 & 0.3 & $<0.1$ & 0.1 & $<1.0$ \\
\hline GE-ratio & $0.5-5.9$ & $0.8-4.1$ & 1.6 & 1.7 & & & \\
\hline Monocytes & $0-8.5$ & $0-6.0$ & 2.0 & 2.2 & 0.3 & 1.3 & $<1.0$ \\
\hline ME ratio & $0.6-6.2$ & $0.8-4.1$ & 1.6 & 1.8 & 2.3 & & \\
\hline Male & $0.6-6.1$ & $0.8-4.0$ & 1.6 & 1.8 & & 2.1 & \\
\hline Female & $0.6-6.2$ & $0.8-4.2$ & 1.7 & 2.0 & & 2.8 & \\
\hline Lymphocytes & $1.0-38.5$ & $5.5-23.2$ & 13.2 & 13.6 & 16.2 & 13.1 & 13.0 \\
\hline Plasma cells & $0-17.5$ & $0-7.0$ & 2.3 & 2.6 & 1.3 & 0.6 & 1.0 \\
\hline
\end{tabular}

The calculation of GE (granulopoiesis/erythropoiesis) and ME (myelopoiesis/erythropoiesis) ratios included all stages of maturation in the individual lines: myeloblast to segmented granulocyte for G, plus monocytes for M, and proerythroblast to orthochromatic erythroblast for E, respectively. $m$ male, $f$ female count, we detected out-of-limit values in $25 \%$ and $16 \%$ of the cases.

\section{Bone marrow evaluations}

Cellularity was diagnosed as normal, reduced, or increased in $190(80 \%), 42(18 \%)$, and $4(2 \%)$ cases, respectively. Thirty-seven out of 42 hypocellular marrow samples were from younger donors aged up to 39 years. A normal content of megakaryocytes was found in 210 specimen $(89 \%)$, while hypoplasia or hyperplasia of megakaryopoiesis was seen in $8(3 \%)$ and $18(8 \%)$ of cases.

Table 3 shows the results of the differentiated cell counts in the bone marrow. The right part of this table contains findings from previous studies for comparison.
Table 4 summarizes the $p$ values for the relevance of different factors that possibly influence hematopoiesis. Gender and body mass index did significantly influence hematopoiesis, whereas age did not. Compared with women, men had significantly more erythropoiesis $(p=$ 0.0003 ) resulting in lower GE and ME ratios, but less lymphopoiesis. Increased BMI was correlated with erythropoiesis and inversely related to the neutrophils and therefore affected the GE/ME ratio too. In smokers, neutrophilic granulopoiesis was significantly increased, and regular physical activity and blood donation lead to an expansion of erythropoiesis. In addition, blood donation led to reduced numbers of monocytes and lymphocytes. The intake of hormonal contraceptives was associated with lower numbers of mature neutrophils and an increase in lymphocytes in female donors. 
Table 4 Univariate evaluation of factors with possible impact on hematopoiesis

\begin{tabular}{|c|c|c|c|c|c|c|c|c|c|}
\hline $\begin{array}{l}\text { Lineage and } \\
\text { maturation }\end{array}$ & Gender & Age & BMI & Smoking & $\begin{array}{l}\text { Alcohol } \\
\text { daily }\end{array}$ & $\begin{array}{l}\text { Physical } \\
\text { activity }\end{array}$ & $\begin{array}{l}\text { Blood } \\
\text { donation }\end{array}$ & $\begin{array}{l}\text { Allergic } \\
\text { diathesis }\end{array}$ & $\begin{array}{l}\text { Hormonal } \\
\text { contraception }\end{array}$ \\
\hline Erythroblasts (total) & 0.0003 & 0.2391 & 0.0009 & 0.0722 & 0.6211 & 0.0328 & 0.0014 & 0.1969 & 0.2864 \\
\hline Proerythroblast & 0.8429 & 0.2192 & 0.3975 & 0.5901 & 0.1178 & 0.8847 & 0.5500 & 0.5964 & 0.6122 \\
\hline Basophilic & 0.3023 & 0.5864 & 0.0080 & 0.0489 & 0.5169 & 0.0491 & 0.3877 & 0.1532 & 0.2394 \\
\hline Polychromatophilic & 0.0126 & 0.2486 & 0.2394 & 0.1248 & 0.6251 & 0.1105 & 0.0006 & 0.6768 & 0.6759 \\
\hline Orthochromatic & 0.0086 & 0.4648 & 0.0243 & 0.7806 & 0.6066 & 0.6028 & 0.7834 & 0.3118 & 0.0693 \\
\hline Granulocytes (total) & 0.2028 & 0.8452 & $<0.0001$ & 0.0086 & 0.5027 & 0.0961 & 0.3296 & 0.0425 & 0.0289 \\
\hline Myeloblast & 0.0537 & 0.5637 & 0.0212 & 0.1275 & 0.0131 & 0.6628 & 0.6389 & 0.8523 & 0.7451 \\
\hline Promyelocyte & 0.1488 & 0.6953 & 0.5145 & 0.9388 & 0.1955 & 0.8655 & 0.7976 & 0.1217 & 0.1857 \\
\hline Myelocyte & 0.6845 & 0.4012 & 0.7894 & 0.3826 & 0.5081 & 0.3786 & 0.5410 & 0.2343 & 0.7557 \\
\hline Metamyelocyte & 0.0928 & 0.3953 & 0.0350 & 0.5650 & 0.5585 & 0.5555 & 0.2481 & 0.9606 & 0.7755 \\
\hline Band & 0.7724 & 0.8982 & 0.0822 & 0.0874 & 0.0879 & 0.4039 & 0.2370 & 0.0029 & 0.4002 \\
\hline Segmented & 0.0063 & 0.3104 & 0.0001 & 0.3505 & 0.3731 & 0.0996 & 0.3014 & 0.5780 & 0.0134 \\
\hline Eosinophils & 0.3825 & 0.3641 & 0.3025 & 0.3256 & 0.6372 & 0.0833 & 0.5524 & 0.0526 & 0.1014 \\
\hline Basophils & 0.1463 & 0.1433 & 0.4304 & 0.1522 & 0.4788 & 0.6771 & 0.5159 & 0.6520 & 0.0672 \\
\hline GE-ratio & 0.0060 & 0.5151 & 0.0017 & 0.0236 & 0.5450 & 0.1341 & 0.0398 & 0.1484 & 0.2052 \\
\hline ME ratio & 0.0060 & 0.4881 & 0.0021 & 0.0225 & 0.5274 & 0.1541 & 0.0246 & 0.1521 & 0.2588 \\
\hline Monocytes & 0.9012 & 0.8026 & 0.6173 & 0.7332 & 0.3714 & 0.1992 & 0.0010 & 0.4785 & 1.000 \\
\hline Lymphocytes & 0.0006 & 0.0971 & 0.4337 & 0.4595 & 0.3745 & 0.0929 & 0.0031 & 0.1257 & 0.0205 \\
\hline Plasma cells & 0.0257 & 0.0131 & 0.3774 & 0.2670 & 0.2094 & 0.9923 & 0.8993 & 0.4711 & 0.9009 \\
\hline
\end{tabular}

Significant test results $(p<0.05)$ are delighted in italics. Granulocytes (total) includes also eosinophils and basophils. For the definition of GE and ME ratio see legend to Table 3

\section{Interrater reliability}

As shown in Table 5, the results differed substantially between the investigators. The highest values for reliability were achieved for the assignment of cells to the different hematopoietic cell lines and cellularity, while single-cell diagnoses varied in a higher degree. There was also a substantial impact of the investigator on the variability of counting, ranging from $<1 \%$ for eosinophils to $58 \%$ for basophilic erythroblasts.

\section{Discussion}

Our study is the largest and most comprehensive examination of physiological hematopoiesis published so far. There are some differences with respect to the number of included individuals, and preparation and assessment of the marrow samples as well between the data reported by Wintrobe [1, 2], Bain [3], Diem [4], and this study (Table 3). The results were cited by Wintrobe based on aspirates from only 12 males, on whom sternal punctures were performed, a procedure that is largely abandoned today. The study by Diem included a higher number of subjects, but did provide neither genderspecific information nor reported the site of interventions.
The references described in the papers differ mainly in the erythroblastic line and with respect to the neutrophilic cell counts. The number of erythroblasts we found was higher than the other authors did. However, the higher proportion of erythropoietic cells in males compared with women had been reported previously. In contrast, the total amount of granulopoietic cells in our series was lower than in the other papers. A difference between the male and female cohort concerning the mature neutrophils as described by Bain we found only for the segmented cells. There were also slightly different results in both lines, erythropoietic and granulocytic, for the proportions of individual maturation stages. This might be attributable to the more difficult and in some extent subjective single-cell diagnoses, which corresponds to the results of the interrater reliability tests. However, the number of myeloblasts, which is probably one of the most important features for the diagnosis in myelodysplasias and leukemias, was not different to the previous reports.

Among the other factors with possible relevance to the hematopoiesis, the physical constitution had a stronger impact than age. The increased erythroblast counts in overweight and obese individuals may be a consequence of a higher need for oxygen supply. Pronounced erythropoiesis after blood donation and due to regular physical activities is not surprising, and the increase in neutrophilic cells in smokers is a known 
Table 5 Impact of investigators on test results

\begin{tabular}{llc}
\hline Lineage and maturation & ICC & Krippend alpha \\
\hline Cellularity & 0.012 & 0.3822 \\
Megakaryopoiesis & 0.000 & 0.3270 \\
Erythroblasts (total) & 0.027 & 0.3483 \\
Proythroblast & 0.356 & -0.1292 \\
Basophilic & 0.582 & -0.1699 \\
Polychromatophilic & 0.311 & 0.0130 \\
Orthochromatic & 0.108 & -0.0300 \\
Granulocytes (total) & 0.011 & 0.3409 \\
Myeloblast & 0.233 & 0.0242 \\
Promyelocyte & 0.530 & -0.1691 \\
Myelocyte & 0.196 & 0.0823 \\
Metamyelocyte & 0.346 & -0.0881 \\
Band & 0.292 & -0.0093 \\
Segmented & 0.275 & 0.1271 \\
Eosinophils & 0.009 & 0.3410 \\
Basophils & 0.049 & 0.0179 \\
Monocytes & 0.412 & -0.0854 \\
Lymphocytes & 0.059 & 0.2528 \\
Plasma cells & 0.132 & 0.2070 \\
\hline
\end{tabular}

*IC-intra class correlation

Krippend alpha-Krippendorff's alpha

Krippendorff's alpha characterizes interrater reliability. A value of zero indicates perfect random disagreement, whereas $a$ value of 1.0 indicates perfect agreement. Alpha can be negative when investigators consistently disagree, use different coding instructions or having conflicting understanding of them

Intra-class-correlation (ICC) estimates the proportions of variance due to the investigators. A value of zero indicates no impact; a value of 1.0 indicates that the investigators only explain variances

phenomenon. In contrast, the pathophysiology behind the shifts of neutrophils and lymphocytes caused by oral contraceptives remains unclear. The frequent use of alcoholic beverages induces dyspoetic changes mainly in the erythroblasts. However, we did not found numeric changes within the hematopoietic lines in our study. To find the majority of hypocellular marrow samples in younger donors was an unexpected result and the interpretation is difficult.

In summary, except for elaborated differences mentioned above, we could confirm in a larger cohort the bone marrow values reported by Bain, which many laboratories use as references.

Because disorders of the hematopoietic system mainly affect patients above the age of 60 years, the lack of individuals out of this population represents the major limitation in our study. Data on bone marrow values in elderly individuals are rare. Samples from patients above the age 50 years are actually subject to another examination. Furthermore, the number of available observations in the analyzed subgroups is too small to draw definite conclusions.
The study also shows that cytological findings are highly subjective and influenced by the investigators. In this series, their experience in cytological diagnostics ranged from 2 to 10 years. If digital diagnostic devices using artificial intelligence systems might be helpful not only in terms of efficacy but also in obtaining objective information is doubtful as even the today available blood analyzers are not able to make precise cell diagnosis in pathologic situations.

Acknowledgments We thank all the volunteers for their willingness to donate hematopoietic stem cells and bone marrow for unknown people suffering from cancer. We thank also the donors for their participation in this study. Special thanks go to the excellent work of our medicaltechnical assistants: Christiane Külper, Kerstin Ackermann, Jana Bornhäuser, Heidrun Zengler, Rita Scheffler, and Bianca Umlauft.

Authors' contributions All authors contributed substantially to this work. The specific contributions are as follows: SP and FK collected bone marrow, performed bone marrow evaluation, interpreted data, and wrote the manuscript. SW performed bone marrow evaluation and commented on manuscript. GE gave organizational support, interpreted results, collected bone marrow, and commented on manuscript. MK performed statistical analysis, interpreted data, and commented on manuscript. RO collected bone marrow, did predonation health check-up and follow-up, and commended on manuscript. US obtained IRB permission, collected bone marrow, did predonation health check-up and follow-up, and commented on the manuscript. MS collected bone marrow and commented on manuscript. MB collected bone marrow and commented on manuscript. GR was involved in donor work-up, gave organizational support, and commended on manuscript. All authors approved the final manuscript.

Funding Open Access funding enabled and organized by Projekt DEAL.

Data availability The slides have been archived at Medical Department I of Dresden University Hospital and all data are available in electronic files. The statistical analyses can be presented as PDF file from statistic program $R \circledast$.

\section{Compliance with ethical standards}

Conflict of interest The authors declare that they have no conflict of interest.

Ethical approval Marrow harvesting and evaluation of hematopoiesis were approved by the institutional review board (EK 240102007) of the Technical University of Dresden. All procedures followed were in accordance with the ethical standards of the responsible committee on human experimentation (institutional and national) and with the Helsinki Declaration of 1975 as revised in 2008.

Consent to participate All donors gave written informed consent for harvest and marrow examination.

Consent for publication All authors have checked this manuscript and declared their consent for publication.

Code availability We used statistic program $R \bowtie$ version 3.5.3. for data analyses. The investigators performed the microscopic evaluations by Nikon Eclipse E600 Microscope. 
Open Access This article is licensed under a Creative Commons Attribution 4.0 International License, which permits use, sharing, adaptation, distribution and reproduction in any medium or format, as long as you give appropriate credit to the original author(s) and the source, provide a link to the Creative Commons licence, and indicate if changes were made. The images or other third party material in this article are included in the article's Creative Commons licence, unless indicated otherwise in a credit line to the material. If material is not included in the article's Creative Commons licence and your intended use is not permitted by statutory regulation or exceeds the permitted use, you will need to obtain permission directly from the copyright holder. To view a copy of this licence, visit http://creativecommons.org/licenses/by/4.0/.

\section{References}

1. Osgood EE, Seaman AJ (1944) The cellular composition of bone marrow as obtained by sternal puncture. Physiol Rev 24:46-69

2. Perkins SL (2009) Examination of the blood and bone marrow. In: Greer JP, Foerster J, Rodgers GM, Parashevas F, Glader BE, Arber DA, Means RT (eds) Wintrobe's Clinical Hematology, 12th edn

3. Bain BJ (1996) The bone marrow aspirate of healthy subjects. Br J Haematol 94(1):206-209

4. Diem H (2012) Referenzwerte der Zellzusammensetzung im Knochenmark (Aspiration). In: Haferlach T, Bacher U, Theml H, Diem H (eds) Taschenatlas der Hämatologie. Georg Thieme Verlag, Stuttgart, New York, p 70

5. Bush K, Kivlahan DR, McDonell MB, Fihn SD, Bradley KA (1998) The AUDIT alcohol consumption questions (AUDIT-C): an effective brief screening test for problem drinking. Ambulatory Care Quality Improvement Project (ACQUIP). Alcohol Use Disorders Identification Test. Arch Intern Med 158(16):1789-1795

6. Hapke U, VdL E, Gaertner B (2013) Alcohol consumption, at-risk and heavy episodic drinking with consideration of injuries and alcohol-specific medical advice: results of the German Health Interview and Examination Survey for Adults (DEGS1). Bundesgesundheitsbl Gesundheitsforsch Gesundheitsschutz 56(56):809-813

7. Langen U, Schmitz R, Steppuhn H (2013) Prevalence of allergic diseases in Germany: results of the German Health Interview and Examination Survey for Adults (DEGS1). Bundesgesundheitsbl Gesundheitsforsch Gesundheitsschutz 56(5-6):698-706
8. Lampert T, von der Lippe E, Muters S (2013) Prevalence of smoking in the adult population of Germany: results of the German Health Interview and Examination Survey for Adults (DEGS1). Bundesgesundheitsbl Gesundheitsforsch Gesundheitsschutz 56(5-6):802-808

9. Krug S, Jordan S, Mensink GB, Muters S, Finger J, Lampert T (2013) Physical activity: results of the German Health Interview and Examination Survey for Adults (DEGS1). Bundesgesundheitsbl Gesundheitsforsch Gesundheitsschutz 56(56):765-771

10. Swerdlow SH, Campo E, Harris NL (2008) WHO classification of tumours of haematopoietic and lymphoid tissues, 4th edn. IARC, Lyon

11. Lee SH, Erber WN, Porwit A, Tomonaga M, Peterson LC, International Council for Standardization In H (2008) ICSH guidelines for the standardization of bone marrow specimens and reports. Int J Lab Hematol 30(5):349-364

12. Bain BJ, Bates I, Laffan AM, Lewis SM (eds) (2012) Practical Haematology, 11th edn. Churchill Livingstone, Elsevier, London

13. Bain BJ, Clark DM, Wilkins BS (2019) Bone marrow pathology, 5th edn. Wiley-Blackwell, London

14. Ryan DH (2010) Examination of the marrow. In: Kaushansky K, Lichtman MA, Beutler LE, Kipps TJ, Seligsohn U, Prchal J (eds) Williams Hematology, 8th edn. McGraw-Hill Companies, New York City, pp S. 25-S. 40

15. Fuchs R, Staib P (Hrsg)(2010) Manual Hämatologie. Nora-Verlag $\mathrm{GmbH}$, Berlin

16. Löffler H, Rastetter J, Haferlach T (Hrsg.) (1999) Atlas der klinischen Hämatologie. Springer-Verlag, Berlin, Heidelberg, New York

17. R Core Team (2019) A language and evironment for statistical computing. R Foundation for Statistical Computing, Vienna. https://www.R-project.org/. Accessed 17 April 2020

18. Hyndman RJ, Fan Y (1996) Sample quantiles in statistical packages. Am Stat 50(4):361-365

19. Krippendorff K (1970) Estimating the reliability, systematic error, and random error of interval data. Educ Psychol Meas 30:61-70

20. Gelman A, Hill J (2007) Data analysis using regression and multilevel / hierarchical models. Cambrige University Press, Cambridge

Publisher's note Springer Nature remains neutral with regard to jurisdictional claims in published maps and institutional affiliations. 